\title{
Rare presentation of a case of primary parasitic leiomyoma with concurrent uterine leiomyomas
}

\author{
Kalpana B.*, Soumya R. Panda
}

Department of Reproductive Medicine, Guru Hospital Madurai, Tamil Nadu, India

Received: 21 March 2018

Accepted: 21 April 2018

\section{*Correspondence:}

Dr. B. Kalpana,

E-mail: balamurugan_kalpana@rediffmail.com

Copyright: () the author(s), publisher and licensee Medip Academy. This is an open-access article distributed under the terms of the Creative Commons Attribution Non-Commercial License, which permits unrestricted non-commercial use, distribution, and reproduction in any medium, provided the original work is properly cited.

\begin{abstract}
Uterine leiomyomas are the most common pelvic benign tumours affecting women of reproductive age group. Parasitic leiomyoma is a type of leiomyoma which has been completely detached from uterus and is having independent blood supply from nearby structures, it's attached with. Parasitic leiomyoma is regarded as a sub-type of subserosal fibroid by some authors. While others consider it as a complication of uterine procedures being performed for some type of uterine pathology. Here we are reporting a rare case of primary parasitic leiomyoma with concurrent multiple uterine leiomyomas that were managed by laparoscopic myomectomy. They create clinical dilemma due to their tendency to mimic as other pelvic tumours. So parasitic fibroids must be kept in the differential diagnosis of every case of abdominopelvic mass. Finally, it can be a rare complication of morcellation procedure performed for myoma retrieval and hence caution should exercise during such procedures.
\end{abstract}

Keywords: Abdomino pelvic mass, Morcellation, Parasitic leiomyoma

\section{INTRODUCTION}

Uterine leiomyomas are the most common pelvic benign tumours affecting women of reproductive age group with incidence of around 50\% found at autopsy. ${ }^{1}$ Parasitic or wandering leiomyomas are very rare extrauterine benign tumours that have been categorized as Type 8 leiomyomas with no myometrial involvement and uterine attachment as per FIGO classification system. ${ }^{2}$ They can be classified further as primary spontaneous and secondary parasitic myomas (which develop after myomectomy procedures). Only few cases of primary parasitic leiomyomas have been reported in literature till date. In contrast, incidence of secondary parasitic leiomyoma is rising. Management of a parasitic leiomyoma becomes challenging for both the treating physician and the histopathologist. ${ }^{3}$ The etiology is unknown, however iatrogenic cause is suggested. ${ }^{3}$ Here we are reporting a rare case of primary parasitic leiomyoma with concurrent multiple uterine leiomyomas that were managed by laparoscopic myomectomy.

\section{CASE REPORT}

A 31-year-old female presented at our hospital for vague pain in hypogastrium. She was a case of secondary infertility and diagnosed to have multiple myomas of uterus as on ultrasonography. She was A3 and married for 8 years.

All of her previous three pregnancies were left sided ectopic pregnancies for which she was managed medically two times and underwent left sided salpingectomy for the third pregnancy.

She was menstruating regularly with normal cycle length and duration of flow. Rest of her general physical examination were within normal limits. 
On per abdominal examination a firm irregular lump was palpable just above pubic symhysis. On bimannual examination this lump was found to be 12-14 weeks size, irregular and firm in consistency.

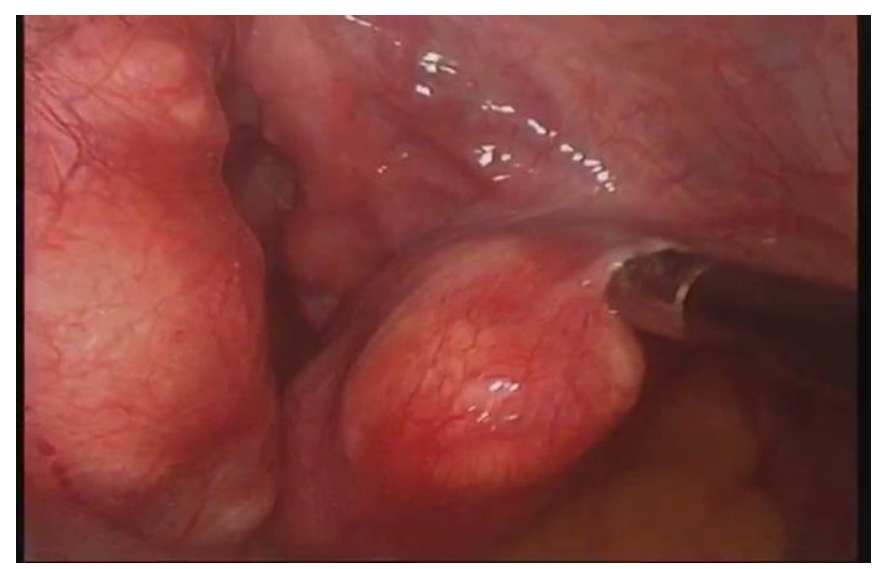

Figure 1: Showing the position of parasitic fibroid.

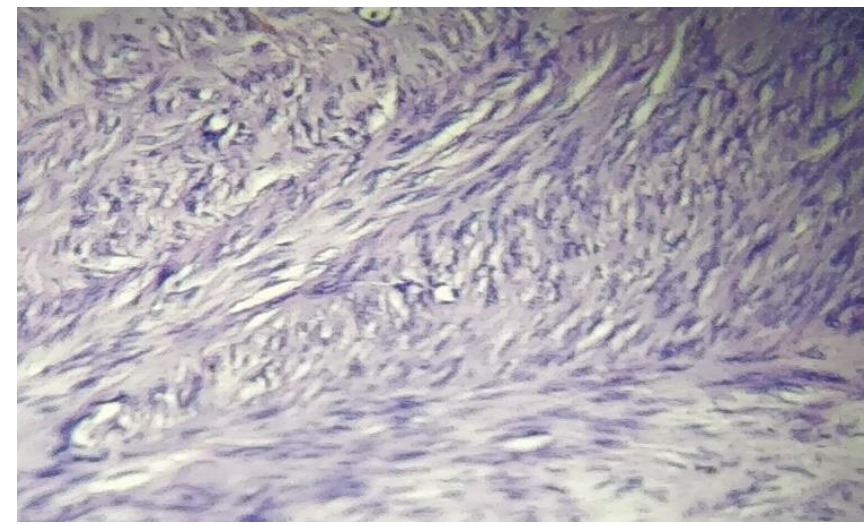

Figure 2: Histological picture of parasitic fibroid specimen showing spindle cells arranged in bundles suggestive od fibroid uterus.

These findings were consistent with the provisional diagnosis of multiple myomas of uterus. Ultrasonography reported three subserous fibroids of size $4.5 \times 3.5,3.7 \mathrm{x}$ 2.5 and $2.7 \times 2.2 \mathrm{~cm}$. Based on these findings we planned laparoscopic myomectomy for this patient.

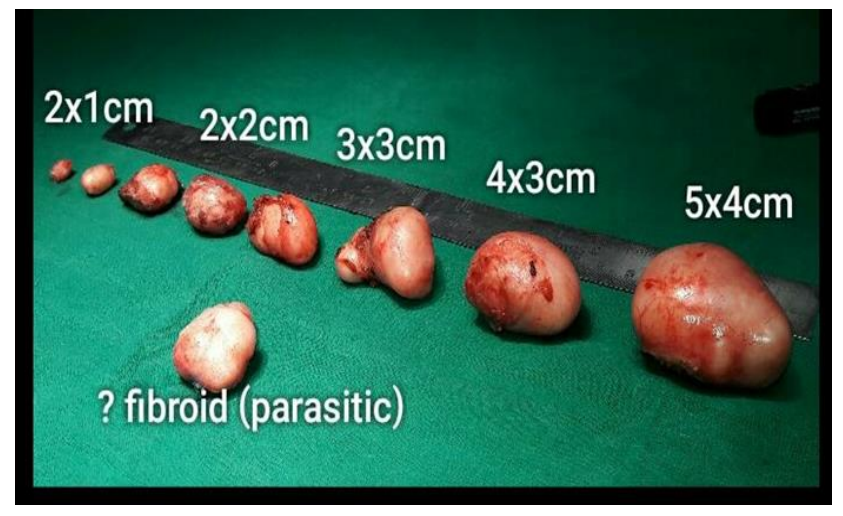

Figure 3: Myomectomy specimens.
On laparoscopy there were a total of eight firoids covering anterior surface, the fundus and posterior surface of uterus. Apart from these eight there was another mass probably a parasitic fibroid located at the right infundibulo pelvic ligament (Figure 1).

Finally, laparoscopic myomectomy done for all the fibroids and all the masses were removed through colpotomy incision. On histopathology examination all masses including the one located at infundibulo pelvic ligament were confirmed as myomas and hence the latter proved to be a parasitic fibroid (Figure 2 and 3).

\section{DISCUSSION}

Leiomyomata (uterine fibroids) are the most common tumors of the female pelvis. ${ }^{1}$ Parasitic leiomyoma is a type of leiomyoma which has been completely detached from uterus and is having independent blood supply from nearby structures, it's attached with. ${ }^{4,5}$ Furthermore, large parasitic fibroid might outgrow its new blood supply and undergo degeneration. The common types of degeneration are hyaline, cystic, mucoid and red. ${ }^{6,7}$ In our case there was areas of hyaline degeneration. As far as areas of prevalence is concerned African American women are reported to be more commonly affected than Caucasians. ${ }^{8}$ Parasitic leiomyoma is regarded as a subtype of subserosal fibroid by some authors. ${ }^{3,9}$ Others consider it as a complication of uterine procedures being performed for some type of uterine pathology. 3,8 Literatures have only few reported cases, most of them reported in last few decades secondary to increased laparoscopic procedures of the uterus. ${ }^{8}$ In a study by Kimberly and his colleagues out of 12 patients ten patients had history of previous abdominal surgery and eight had history of previous morcellation procedures. ${ }^{11}$ $\mathrm{Lu}$ et al. presented six such cases, all of which had history of laparoscopic hysterectomy or myomectomy with power morcellation. ${ }^{11,12}$ Similarly in a retrospective study out of 423 women, in whom morcellation was done, $0.9 \%$ developed Parasitic leiomyoma. The authors concluded morcellation to be a risk factor for development of Parasitic leiomyoma. Therefore, a careful inspection and thorough washing of abdominal and pelvic cavities should be done after the procedure. ${ }^{13}$ In present case the patient had no history of any previous surgery. Only few cases of primary spontaneous parasitic myomas have been reported in literature. ${ }^{13,14}$ Like our case concomitant occurrence of uterine leiomyoma with parasitic leiomyoma has also been reported albeit rarely. ${ }^{15,16}$ Radiological imaging plays a vital role for diagnosis of such cases. Whorled appearance, with variable echogenicity depending on the extent of degeneration, fibrosis, and calcification are the typical ultrasonological features for a case of leiomyoma. Ovarian masses (primary tumour or metastatic disease), broad ligament cysts, and lymphadenopathy are the common differential diagnosis for parasitic leiomyomas. Transvaginal Ultrasonography may be of great help in diagnosing broad ligament leiomyomas because it allows 
clear visual separation of the uterus and ovaries from the mass. MR imaging, with its multiplanar imaging capabilities, also may be extremely useful for differentiating broad ligament leiomyomas from tuboovarian masses and from broad ligament cysts and also in differentiating them from solid malignant pelvic tumors. ${ }^{17}$ Still some of the cases of parasitic fibroids cannot be diagnosed preoperatively and only to be diagnosed during surgery as is the case of ours.

\section{CONCLUSION}

Parasitic leiomyomas are very rare extra uterine tumors which are known not only for their rarity but also for their atypical clinical presentation and unusual location. They create clinical dilemma due to their tendency to mimic as other pelvic tumours. So parasitic fibroids must be kept in the differential diagnosis of every case of abdominopelvic mass. Awareness should be created for the rare complication of morcellation (iatrogenic parasitic leiomyoma). A thorough inspection and washing of peritoneal cavity must be carried out during morcellation procedures.

\section{Funding: No funding sources Conflict of interest: None declared Ethical approval: Not required}

\section{REFERENCES}

1. Jones HW, Rock JA. Leiomyomata Uteri and Myomectomy. In: Jones HW, eds. Te Linde's Operative Gynecology. 11th ed. Philadelphia, PA: Wolters Kluwer. 2015:658-62.

2. Berek JS. Uterine Fibroids. In: Berek JS, eds. Berek \& Novak's Gynecology. 15th ed. Philadelphia, PA:Lipincott Williams \& Wilkins. 2013:444-5.

3. Grover A, Bhalla S. Parasitic leiomyoma: a rare complication following laparoscopic myomectomy with review of literature. Curr Med Res Pract. 2015; 5(6):278-81.

4. Takeda A, Mori M, Sakai K. Parasitic peritoneal leiomyomatosis diagnosed 6 years after laparoscopic myomectomy with electric tissue morcellation: report of a case and review of the literature. J Minim Invasive Gynecol. 2007;14:770-5.

5. Odofin O, Nasir N, Satyadas T. An unusual case of ectopic or parasitic leiomyoma excised by laparoscopic surgery. Int Surg. 2004;89:161-3.
6. Thian YL, Tan KH, Kwek JW. Leiomyomatosis peritonealis disseminata and subcutaneous myomae a rare complication of laparoscopic myomectomy. Abdom Imaging. 2009;34: 235-8.

7. Abdel Rahman A, Anas S, Muhammad R. Parasitic leiomyoma: a rare cause of inguinal mass in females. Saudi Med J. 2011;32(6): 633-5.

8. Sarmalkar M, Nayak A, Singh N, Mehendale M, Dixit P. A rare case of primary parasitic leiomyoma mimicking as ovarian mass: a clinical dilemma. Int. J. Reprod. Contracept. Obstet. Gynecol. 2016;5(2): 545-8.

9. Schaudien D, Müller, JM, Baumgärtner W. Omental leiomyoma in a maleadult horse, Vet. Pathol. 2007;44(5): 722-6.

10. Kimberly A, Nezhat C. Parasitic myomas. Obstet. Gynecol. 2009;114(3): 611-5.

11. Lu B, Xu J, Pan Z. Iatrogenic parasitic leiomyoma and leiomyomatosisperitonealis disseminata following uterine morcellation, J Obstet Gynaecol Res. 2016;42(8):990-9.

12. Gaspare C, Roberta G, Gloria C, Edgardo S. Parasitic myomas after laparoscopic surgery: an emerging complication in the use of morcellator? Description of four cases. Fertil Steril. 2011;96(2);90-6.

13. Mandal D, Dattaray C, Roy S. Spontaneous Parasitic Leiomyoma: A Rare Clinical Experience. J South Asian Feder Obst Gynae. 2013;5(2):85-6.

14. Sreelatha S, Kumar A, Nayak V, Punneshetty S. A rare case of primary parasitic leiomyoma. Int $\mathbf{J}$ Reprod Contracept Obstet Gynecol. 2013;2(3):422-4.

15. Abdel-Gadir A, Arancis ND, Oyawoye OO, Chander BP. Secondary amenorrhoea with high inhibin B level caused by parasitic ovarianleiomyoma, Gynecol. Endocrinol. 2010;26(2):93-5.

16. Nappi L, Bettocchi S, Carriero C, Ceci O, Vimercati A, Resta L. Large parasitic leiomyoma of the broad ligament. J Gynecol Surg. 2004;20(3):97-102.

17. Najila F, Alampady K, Prasad S, David M. Leiomyomas beyond the uterus: unusual locations, rare manifestations. Radiographics. 2008;28:193148 .

Cite this article as: Kalpana B, Panda, SR. Rare presentation of a case of primary parasitic leiomyoma with concurrent uterine leiomyomas. Int J Reprod Contracept Obstet Gynecol 2018;7:2503-5. 